\title{
Acute subdural effusion in vasculitis
}

\section{Seetharam Raghavendra, Vidya Madavana Venugopal Kamath, C. Sarada, Ashalatha Radhakrishnan, Chandrasekharan Kesavadas ${ }^{1}$, Thamburaj Krishnamoorthy ${ }^{1}$}

Department of Neurology and Department of Imaging Sciences and Interventional Radiology1, Sree Chitra Tirunal Institute for Medical Sciences and Technology, Trivandrum, kerala,India

\begin{abstract}
We report a 29-year-old man with a unique presentation of vasculitis as acute unilateral subdural effusion and meningoencephalitis. Magnetic resonance imaging showed a brainstem lesion that spread to the thalamus over time. There were no systemic features of vasculitis other than a positive pathergy test. Histopathological examination from the pathergy site showed neutrophilic infiltrate and leucocytoclastic vasculitis. The condition was steroid responsive and he remained in remission at two years' follow-up. The anatomy of the brainstem lesion, absence of other inflammatory and infective conditions on evaluation suggests a vasculitic pathology either as primary central nervous system angiitis or as neurological presentation of systemic vasculitis like Behçet's disease although the international diagnostic criteria for Behçet's were not fulfilled.
\end{abstract}

Key words: Pathergy test, subdural effusion, vasculitis

Vasculitis affecting the central nervous system (CNS) very rarely presents as acute or chronic meningoencephalitis. ${ }^{[1]}$ Very few cases of subdural effusion in vasculitis are reported in the literature. ${ }^{[2-5]}$ We report here a case of vasculitis affecting the CNS manifesting as acute unilateral subdural effusion and meningoencephalitis.

\section{Case Report}

A 29-year-old man of Indian origin presented with acute global headache of one-week duration without any signs of raised intracranial tension. He had no significant antecedent medical or neurological illnesses. No history of oral or genital ulcerations or ophthalmic symptoms was forthcoming. There was no history of any recent head injury or trauma. Detailed general physical and neurological examination did not reveal any abnormality.

Computed tomography (CT) scan of head revealed a right frontotemporal subdural effusion [Figure 1A].
Over the next three days, he developed ataxia towards the right and bilateral abducens palsy. Magnetic resonace imaging (MRI) brain revealed in addition to the effusion, a right pontomedullary lesion, hyperintense on T2 weighted images (T2WI) [Figure 1B-D]. Magnetic resonance venogram was normal. Cerebrospinal fluid (CSF) examination showed 520 cells/cmm (lymphocytes 80\%, polymorphs 20\%), protein of $48 \mathrm{mg} / \mathrm{dL}$ and normal sugar. Plenty of RBCs was also reported. The CSF gram, fungal and AFB stain, CSF VDRL and CSF TB-PCR were negative. Specific test for Borrelia was not done.

All the biochemical investigations, hemogram, ESR, chest X-ray, Mantoux test, serum VDRL, HBsAg, HCV antibodies and HIV-I and II were negative. He was empirically started on a four-drug antitubercular therapy (ATT) (rifampicin $450 \mathrm{mg} /$ day, INH $300 \mathrm{mg} /$ day, pyrazinamide $750 \mathrm{mg} /$ day, ethambutol $800 \mathrm{mg} /$ day) with oral prednisolone $40 \mathrm{mg}$ /day.

Patient remained stable clinically; an MRI brain repeated two months later showed new lesions at the mesencephalo-diencephalic junction with extension into the right middle cerebellar peduncle and sparing the red nuclei [Figure 2A]. Lesions showed ring enhancement on contrast study [Figure 2B]. No evidence of earlier subdural effusion was noted [Figure 2C,D]. A repeat CSF study at this stage was normal. His ATT was modified. Pyrazinamide was stopped. Ciprofloxacin $1500 \mathrm{mg} /$ day and ethionamide $250 \mathrm{mg} /$ day were added. He was continued on prednisolone $40 \mathrm{mg}$ daily. Patient gradually showed improvement over the next two months.

Six months into the illness, steroids were tapered and stopped, following which his condition worsened to the original status and was referred to our institute. Examination showed, in addition to earlier deficits, patchy sensory impairment over the left upper and lower limbs. A repeat CSF study showed 2 cells/cmm with $100 \%$ lymphocytes, normal sugar and mildly elevated proteins (48 $\mathrm{mg} \%$ and $50 \mathrm{mg} \%$ respectively). 


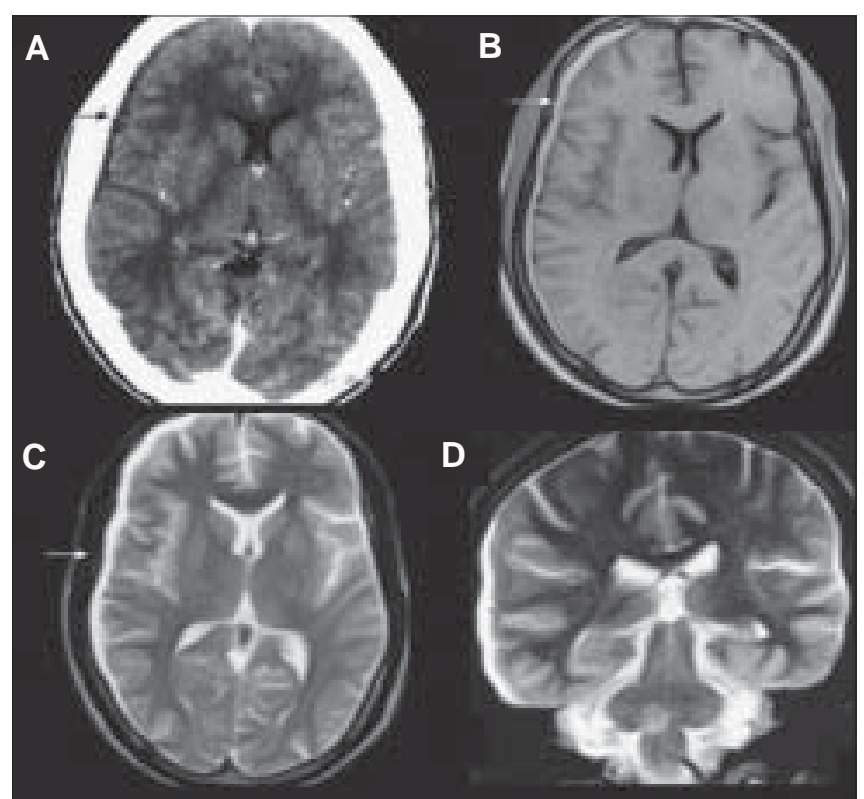

Figure 1: MRI brain performed two months after the initial MRI. Coronal FLAIR image shows a hyperintense lesion at a higher level in the brainstem (A) Post contrast midline sagittal image shows ring enhancement of these lesions after contrast administration (B) Axial T1 weighted (C) and T2 weighted images (D) show the resolution of the subdural collection

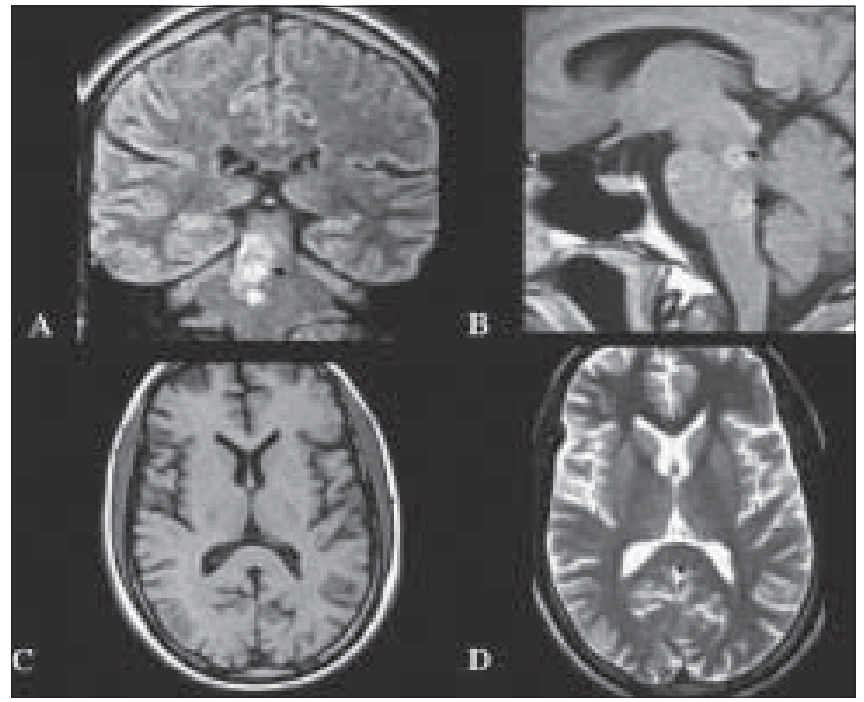

Figure 2: Contrast enhanced axial CT (A) shows a hypodense subdural collection in the right frontal convexity. Axial T1 weighted (B) and T2 weighted images (C) of MRI brain performed three days later shows that the subdural collection is hyperintense. Coronal T2 weighted image

(D) shows hyperintense lesion at the pontomedullary junction

Serum angiotensin converting enzyme (ACE) assay, serum ANA, APLA, RA factor, LE cell test and serum calcium were normal. A pathergy test was pursued that was positive [Figure 3A]. Skin biopsy from the test site favored the diagnosis of vasculitis [Figure 3B,C]. The ATT was withdrawn. Patient was restarted on higher doses of oral steroids (prednisolone $1 \mathrm{mg} / \mathrm{kg} / \mathrm{day}$, $60 \mathrm{mg} /$ day) with which he made a gradual and partial recovery of neurological signs in two weeks. Disabling

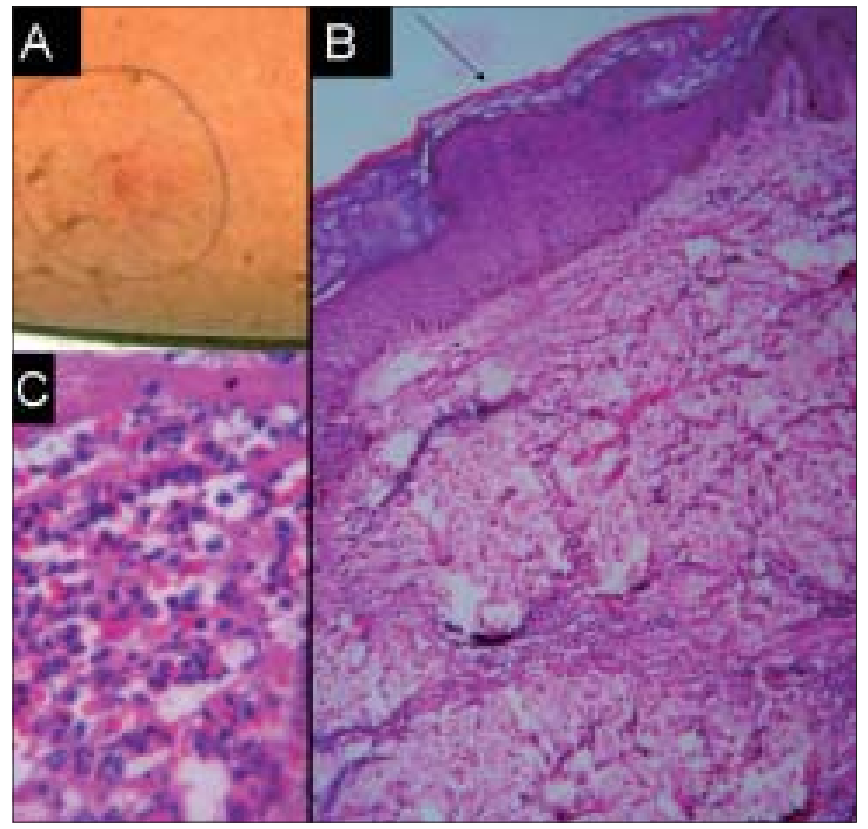

Figure 3: Histopathology from the pathergy site. (A) shows induration and inflammation at the site of needle prick. (B) Histology of the skin shows inflammation in the dermis around the vessels and a crust formation at the site of prick (arrow). (C) Higher magnification shows neutrophilic infiltration, fibrin and leucocytoclasia at the site of vasculitis in the dermis. $B(H \& E, \times 120) C(H \& E, \times 400)$

gait ataxia improved to independent ambulation and scanning dysarthria moderately improved. A marginal improvement in his bilateral sixth nerve palsy was also noted. Sensations returned to normal. Considering the high specificity of positive pathergy test for the diagnosis of Behcet's disease and the relatively low yield of a leptomeningeal biopsy and DSA in making an alternate diagnosis like primary angitis of the CNS(PACNS), it was decided not to subject the patient for these invasive procedures. Moreover, the steroid responsiveness of the disease being well established, it was decided to go in for a close clinical follow-up after consultation with the family.

At two years' follow-up, patient has remained status quo without any new neurological or systemic symptoms or signs on $20 \mathrm{mg}$ of prednisolone.

\section{Discussion}

We hereby present a patient with steroid responsive acute unilateral subdural effusion and meningoencephlitis with a brainstem lesion that later involved the thalamus. There were no other markers for infective process or systemic vasculitis other than a positive pathergy test.

Acute inflammatory subdural effusion has been reported in Kawasaki's disease, systemic sclerosis and Behçet's disease. ${ }^{[2-5]}$ However, in these described cases the subdural effusion was bilateral unlike our patient who had unilateral subdural effusion. Vasculitis of 
the dural vessels and transient subdural venulitis has been attributed as the possible pathology for subdural effusion in these patients. ${ }^{[3,5]}$ Varying affection of the dural vessels could account for unilateral effusion seen in our patient. In addition, in our patient the subdural effusion was associated with meningoencephalitis reflected as CSF abnormalities of mixed pleocytosis, marginally elevated protein and normal glucose. The subdural effusion on MRI was hyperintense on T1 and T2WI signifying an exudative nature of the effusion. The subdural effusion could thus be in part a reflection of this meningitic process also. Moderate lymphocytic pleocytosis of CSF has been observed in pathologically proven cases of PACNS and in patients with neurological involvement in Behçet's disease. ${ }^{[6,7]}$

The sensitivity of the pathergy test is reportedly low, however, the specificity remains very high for the diagnosis of Behçet's disease. ${ }^{[8-10]}$ The sensitivity rates of pathergy test in Indian patients are unknown, but can be assumed to be low.False positivity have been very occasionally reported in non-Hodgkin's lymphoma, Pyoderma granulosum, CML patients on interferon therapy and hairy cell leukemia, which were all ruled out in our patient. ${ }^{[11-13]}$ The histopathology from the pathergy site showed neutrophilic infiltration and leucocytoclasia. Leukoclastic vasculitis has been observed in a variety of conditions like autoimmune diseases, infections with streptococci, staphylococci etc,ulcerative colitis,drugs etc which were essentially ruled out in our patient. Biopsy from the pathergy test site has not shown to increase the sensitivity and specificity of the results, 14 but such histopathology is probably more helpful in a very atypical case as ours than a non-standardized pathergy test.

The patient did not satisfy the international diagnostic criteria for Behçet's disease and neurological manifestations as initial presentation of Behçet's is extremely rare. ${ }^{[15]}$ Gille et al., reported three patients with initial neurological presentation who developed other classical features months or years later. ${ }^{[16]}$ The MRI in our patient was characterized by brainstem affection that is most consistent with Behçet's disease. ${ }^{[17,18]}$ Similar findings may, however, also be expected in other small vessel vasculitis like PACNS. Lymphomatous affection of the CNS also rarely may mimic PACNS. ${ }^{[19]}$ However, on follow-up for two years he remained symptom-free on low-dose steroids, making it unlikely.

During the initial routine follow-up MRI, new brainstem lesions without any additional clinical deficits were observed. In a prospective study of 31 patients with Behçet's disease and neurological involvement, the clinical deficits correlated with MRI but the MRI abnormalities were more disseminated than the clinical findings. ${ }^{[20]}$

\section{Conclusion}

Initial subdural effusion, multifocal neuraxial involvement and meningoencephalitis add to the range of neurological presentation of vasculitis.

\section{References}

1. Tervaert JW, Kallenberg C. Neurologic manifestations of systemic vasculitides. Rheum Dis Clin N Am 1993;19:913-40

2. Bailie NM, Hensey OJ, Ryan S, Allcut D, King MD. Bilateral subdural collections: An unusual feature of possible Kawasaki disease. Eur J Pediatr Neurol 2001;5:79-81.

3. Aoki N. Subdural effusion in the acute stage of Kawasaki disease (Mucocutaneous lymph node syndrome). Surg Neurol 1988;29:216-7.

4. Shaskey DJ, Mijer JF, Williams HJ, Sawitzke AD. Subdural fluid collections: An unusual manifestation of CNS disease in a connective tissue disorder. Clin Rheumatol 1995;14:108-11.

5. Suzuki N, Takeno M, Inaba G. Bilateral subdural effusion in a patient with neuro-Behcet's disease. Ann Rheum Dis 2003;62:374-5.

6. Panda KM, Santosh V, Yasha TC, Das S, Shankar SK. Primary angiitis of CNS: Neuropathological study of three autopsied cases with brief review of literature. Neurol India 2000;48:149-54.

7. Akman-Demir G, Serdaroglu P, Tasçi B. Clinical patterns of neurological involvement in Behcets disease: Evaluation of 200 patients. Brain 1999;122:2171-81.

8. Dilsen N, Koniçe M, Aral O, Ocal L, Inanç M, Gül A. Comparative study of the skin pathergy test with blunt and sharp needles in Behçet's disease: Confirmed specificity but decreased sensitivity with sharp needles. Ann Rheum Dis 1993;52:823-5.

9. Chang HK, Cheon KS. The clinical significance of a pathergy reaction in patients with Behcet's Disease. J Korean Med Sci 2002;17: 371-4.

10. Friedman-Birnbaum R, Bergman R, Aizen E. Sensitivity and specificity of pathergy test results in Israeli patients with Behçet's disease. Cutis $1990 ; 45: 261-4$.

11. Burney IA, Moatter T, Siddiqui T, Yaqoob N. Pathergy in non-Hodgkin lymphoma. J R Soc Med 2003;96:127-9.

12. Budak-Alpdogan T, Demircay, Alpdogan O, Direskeneli H, Ergun T, Oztürk A, \& al. Skin hyperreactivity of Behçet's patients (pathergy reaction) is also positive in interferon alpha-treated chronic myeloid leukaemia patients, indicating similarly altered neutrophil functions in both disorders. Br J Rheumatol 1998;37:1148-51.

13. Kaplan RP, Newman G, Saperia D. Pyoderma gangrenosum and hairy cell leukaemia. J Dermatol Surg Oncol 1987;13:1029-31.

14. Akmaz O, Erel A, Gürer MA. Comparison of histopathologic and clinical evaluations of pathergy test in Behçet's disease. Int J Dermatol 2000;39:121-5.

15. Kidd D, Steuer A, Denman AM, Rudge P. Neurological complications in Behcets syndrome. Brain 1999;122:2183-94.

16. Gille M, Sindic CJ, Laterre PF, De Hertogh P, Hotermans JM, Selak I, \& al. Neurological involvement as manifestation of Behcet's disease: 4 clinical case reports. Acta Neurol Belg 1990;90:233-47.

17. Park KS, Ko HJ, Yoon CH, Park SH, Cho CS, Kim HY, \& al. Magnetic resonance imaging and proton magnetic resonance spectroscopy in neuro-Behcet's disease. Clin Exp Rheumatol 2004;22:561-7.

18. Lee SH, Yoon PH, Park SJ, Park SJ, Kim DI. MRI findings in neurobehcet's disease. Clin Radiol 2001;56:485-94.

19. Williams RL, Meltzer CC, Smirniotopoulos JG, Fukui MB, Inman M. Cerebral MR Imaging in Intravascular Lymphomatosis. A.JNR Am J Neuroradiol 1998;19:427-31.

20. Wechsler B, Dell'lsola B, Vidailhet M, Dormont D, Piette JC, Blétry O, \& al. MRI in 31 patients with Behçet's disease and neurological involvement: Prospective study with clinical correlation. J Neurol Neurosurg Psychiatry 1993;56:793-8.

Accepted on 19-12-2007

Source of Support: Nil, Conflict of Interest: None declared. 